\title{
An innovation resistance factor model
}

\author{
Siti Salwa Mohd Ishak ${ }^{1}$ and Sidney Newton ${ }^{2}$ \\ ${ }^{1}$ Construction Management, School of Housing Building and Planning, Universiti Sains Malaysia, Penang, \\ Malaysia \\ ${ }^{2}$ Construction Management and Property, Faculty of Built Environment, University of New South Wales, \\ Sydney, Australia
}

\begin{abstract}
The process and implementation strategy of information technology in construction is generally considered through the limiting prism of theoretical contexts generated from innovation diffusion and acceptance. This research argues that more attention should be given to understanding the positive effects of resistance. The study develops a theoretical framing for the Integrated Resistance Factor Model (IRFM). The framing uses a combination of diffusion of innovation theory, technology acceptance model and social network perspective. The model is tested to identify the most significant resistance factors using Partial Least Square (PLS) technique. All constructs proposed in the model are found to be significant, valid and consistent with the theoretical framework. IRFM is shown to be an effective and appropriate model of user resistance factors. The most critical factors to influence technology resistance in the online project information management system (OPIMS) context are: support from leaders and peers, complexity of the technology, compatibility with key work practices; and pre-trial of the technology before it is actually deployed. The study provides a new model for further research in technology innovation specific to the construction industry.
\end{abstract}

Keywords: User resistance, technology innovation, diffusion of innovation, technology acceptance model, social network.

Paper type: Research article

\section{Introduction}

The study of information technology (IT) innovation generally takes one of two principal perspectives on how new technologies impact on an organization - the diffusion of innovation (DoI) theory perspective and the technology acceptance model (TAM) perspective. DoI theory considers innovation from the perspective of the technology. It focusses on how particular characteristics of a technology promote or hinder its adoption by different users. The theory applies to all innovations (new products, practices, ideas, etc.). Using DoI theory Rogers (2003) articulated innovations in terms of five key characteristics:

- The relative advantage of the innovation over current technologies/products/ practices/etc.

- The compatibility of the innovation with established technologies/products/etc.

- The perceived complexity of the innovation in terms of implementation/use/etc.

- The availability of the innovation for trialling and testing prior to its deployment.

\footnotetext{
Copyright: Construction Economics and Building 2016. C 2016 Siti Salwa Mohd Ishak and Sidney Newton. This is an Open Access article distributed under the terms of the Creative Commons Attribution 4.0 Unported (CC BY 4.0) License

(https://creativecommons.org/licenses/by/4.0/), allowing third parties to copy and redistribute the material in any medium or format and to remix, transform, and build upon the material for any purpose, even commercially, provided the original work is properly cited and states its license.
}

Citation: Ishak, S.S.M. and Newton, S. 2016. An innovation resistance factor model, Construction Economics and Building, 16(3), 87-103. DOI: http://dx.doi.org/10.5130/AJCEB.v16i3.5164

Corresponding author: Siti Salwa Mohd Ishak; Email - salwaishak@usm.my

Publisher: University of Technology Sydney (UTS) ePress 
- The observable use of the innovation by colleagues or peers, especially senior colleagues.

Following a similar articulation, Moore and Benbasat (1991) developed a survey instrument for use in the evaluation of user perceptions of IT innovations. Their extensive study identified the most important perceived characteristics of an IT innovation affecting the decision of a user to adopt or otherwise a technology to be: how voluntary the use of the technology is; its image; the relative advantage of this technology; compatibility with existing practices; ease of use; opportunity to trial the technology; how demonstrable the results of using the technology appear; and its visibility. These characteristics provide a complement to the DoI theory of Rogers (2003), with the notable additions of image and voluntariness. The image factor relates to what the user considers the technology will highlight in terms of their status in the organisation. Voluntariness refers to whether the user develops some personal interest and perceived agency in the decision to adopt the innovation.

On the other hand, TAM considers innovation from the perspective of the individual user. The particular focus of TAM is on the attitudes of individual users towards a technology and specifically their intention to adopt. The intention to use a new technology generally is considered to depend on the perceived usefulness and ease of use of a technology. TAM has established a variety of models and theoretical concepts to represent individual attitudes to usefulness and ease of use. For example, TAM was first introduced and revised by Davis (1986) and Davis, Bagozzi and Warshaw (1989). Since then it has been extended in various directions, but the core factors have remained relatively robust over time: level of support, quality of training, social influence and individual expectation. Then, in the modified version by Venkatesh and Davis (2000), additional theoretical constructs were added across social influence and cognitive instrumental processes. A unified theory of acceptance and use of technology (UTAUT) extended the original TAM theory, adding four new constructs for: performance expectancy, effort expectancy, social influence, and facilitating condition (Venkatesh et al., 2003).

Both key perspectives have been applied extensively in the literature. Reviews by Legris, Ingham and Collerette (2003) and Jeyaraj, Rottman and Lacity (2006) both noted a strong emphasis on the use of DoI and TAM. A review by Williams et al. (2009) found similar emphasis. Each major review has also challenged the value of such a strong bias in attention towards the earlier stages of 'adopting' and 'accepting' new technology innovations. The lexicons of DoI and TAM both heavily favour adoption, and over-emphasise the aspect of innovation driven by desireability. Such bias limits the opportunity to integrate theories, and underplays the role of social interaction and other key factors implicated in the evolution of innovation.

TAM in particular is criticised because it takes a narrow view of innovation and creates a limited picture of the problem focused on adoption (Benbasat and Barki, 2007). Technological outcomes are contingent, but TAM largely ignores some of the more central characteristics of user sense-making that potentially contribute so significantly to how an innovation is conceptualised and regarded by users. Perhaps most critically, TAM tends to treat user perception as a uniform construct that can be aggregated (Salovaara and Tamminen, 2009). To address this failing and seek to bridge some of the key knowledge gaps, calls have been made for the development of more integrated theoretical frameworks with more of a focus on the factors influencing user resistance (Venkatesh, 2006).

Many studies described resistance as the natural tendency or preference of an individual to avoid change. As such, resistance often has negative, destructive and adversarial connotations. However, by observing the nature and presence of resistance, an organisation can better identify when and how an innovation has significant potential to fail (Davis, 2004; Hartmann and Fischer, 2009; Lapointe and Rivard, 2005; Martinko, Henry and Zmud, 1996; Val and 
Fuentes, 2003; Waddell and Sohal, 1998). From this stance, resistance offers a positive indication of potential to fail. For example, user resistance to a new technology may be wellfounded, but can be masked when the focus is on pushing user adoption and overcoming user resistance. The introduction of resistance has the potential to set the functional properties of a technology in the immediate context of existing work practices. Resistance can be viewed as an important mechanism to better understand how users actually and are likely to respond to new technology innovations at work. For the purposes of this research, resistance is defined as: the actions of a potential user of a new technology implementation that reflect his or her concern or opposition to particular aspects of that technology relative to a given work-practice context.

\section{An integrated resistance factor model}

A number of previous studies have linked resistance to cognitive (Marakas and Hornik, 1996) and behavioural characteristics (Cenfetelli, 2004; Lapointe and Rivard, 2005; Martinko, Henry and Zmud, 1996), and to social and political factors (Joshi, 1991; Kim and Kankanhalli, 2009; Meissonier and Houzé, 2010; Prasad and Prasad, 2000). However, few studies go beyond consideration of resistance taken from a particular perspective: human, social, technical or organisational. The real need is for the different considerations and emphasis of each perspective to be integrated to address resistance more holistically (Davis, 2004; Ferneley and Sobreperez, 2006; Klaus, Wingreen and Ellis, 2010; Laumer and Eckhardt, 2010). For example, Davis (2004) proposed a Social Architecture Factor Model (SAFM), which integrates three different perspectives from the change management literature. Davis (2004) believed that resistance to IT change can be measured effectively by integrating a wide variety of factors, such as: type and scope of change; method and speed of technology introduction; demographic of individual; attitudes, beliefs and fears; and demographic features of the organisation.

Ferneley and Sobreperez (2006) proposed a 'Compliance-Resistance-Workaround' (CRW) model. The CRW model integrates three different resistance behaviours specific to information systems: compliance, resistance and workaround. Based on this combination, Ferneley and Sobreperez (2006) argue that the concept of resistance should be better understood as a consequence of compliance and prescribed use. A compliance approach has the potential to create both positive and negative resistance, often promoting workaround behaviour (e.g. nonuse, sabotage and avoidance of work). Laumer and Eckhardt (2010) proposed the Model of Resistance to IT-induced Organizational Change (MRTOC). This more recent model also draws on a wide range of drivers for user resistance. It includes perspectives of technology acceptance, organisation sciences and managerial psychology. This model considers resistance as a multidimensional problem and believes that outcome factors and process factors are interrelated. The model also posits that outcomes related to work, technology and process are determined directly by factors such as technology perceptions, resistance to change, and process and working routine perceptions.

Attempts to develop an integrated model of user resistance generally share a common basis in different forms of human psychological and behavioural outcomes, broadly resulting from particular antecedents (technical, social, organisational and managerial). However, whilst social factors are often mentioned in the literature they have rarely been recognised explicitly in previous models specific to integration. Social influence and social network factors have been considered more directly in terms of the IoT and TAM, where social interactions are viewed as support mechanisms in the use of technology (Orlikowski, 2000). IoT and TAM are both clear that when innovation support is embedded within social groups, then the use of technology is stabilised and becomes more predictable. The desire to share files with co-workers, attending common training with colleagues, and/or watching co-workers demonstrate new innovations, for examples, are each seen to promote stronger technology adoption on the back of reduced user resistance. 
In summary, DoI and TAM are well-established theories in the context of innovation and have been applied extensively to analyse acceptance, adoption, diffusion and resistance. However, the strong focus of both perspectives is on adoption and implementation. The key considerations of DoI are technology attributes such as advantage, complexity and compatibility. These are not dissimilar to the usefulness and ease of use factors in TAM. DoI and TAM both include aspects of social networks, although TAM adopts a more behavioural, intentions and motivational perspective in comparison. While clearly interrelated, DoI and TAM are rarely applied to study technology innovation implementation in concert.

The potential addition of a social network perspective seeks to address a consistent failure of DoI, TAM and previous integrative models to incorporate social factors more explicitly and directly. This research proposes an integrated resistance factor model (IRFM) that incorporates DoI, TAM and (to recognise social factors) social network threshold (SNT) theory. SNT predicts that an effective diffusion process occurs when individuals have sufficient information to satisfy their personal exposure (threshold) requirements (Valente, 1996). SNT was motivated by the work of Granovetter (1973) and Rogers and Kincaid (1981), and the core threshold concept is applied in this study in terms of personal exposure to innovation. Personal exposure is gained from a range of people (leaders, peers and affiliates) involved in the adoption network of an individual and the communication that links and connects the people within that network. This concept of personal exposure is elaborated in terms of support network in the proposed model.

DoI contributes a number of integration and accessibility factors. Together, DoI and TAM contribute a number of experience and disposition factors. All three theoretical perspectives, but SNT in particular, contribute support network factors. In order to assess the significance of each and every factor in resistance terms, DoI is also used to identify resistance indicators. Figure 1 illustrates the structure and components of the proposed IRFM, along with the relationship of IRFM to its contributing theoretical perspectives.

The integration and accessibility factor associated with an innovation determines how an individual perceives the innovation in a general sense. The construct for the integration and accessibility factor is based primarily on Rogers (2003), extensive work by Moore and Benbasat (1991) and TAM. Integration includes the inherent characteristics of the technology: (1) relative advantage, (2) compatibility and (3) complexity. These factors are relevant to the operability issues of the technology, which can support individuals to conduct work tasks and enhance working collaborations with others. An accessibility factor is concerned with making technology available for (4) learning, (5) trialling and (6) visibility to users.

Derived from the psychology perspective and attitude-behaviour theories, an experience and disposition factor is best considered in terms of a psychological evaluation. Disposition carries the accompanying variables that the model refers to as experience. Six constructs constitute experience and disposition: (1) knowledge of ICTs, (2) use of ICTs, (3) motivation, (4) efficacy, (5) anxiety and (6) power.

The model also includes three constructs forming the support network: (1) leaders, (2) peers and (3) affiliates. A personal network and relationships in the workplace are very important when influencing users to adopt technology (Rogers, 2003; Valente, 1996; Venkatesh et al., 2003). Leaders, close friends, co-workers or supervisors also significantly affect beliefs about the use of a technology (Valente and Davis, 1999). 


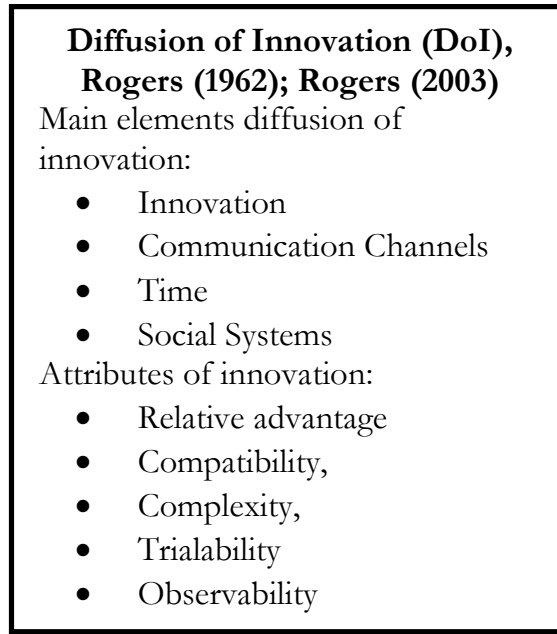

Technology Acceptance Models (TAM), (Davis, 1986; Davis, Bagozzi and Warshaw, 1989) and Unified Theory of Acceptance \& Use of Technology (UTAUT), (Venkatesh et al., 2003)

Main construct in the models:

- Behavioural intention

- Attitude towards using the system

- Perceived usefulness

- Perceived ease of use

- Performance expectancy

- Effort expectancy

- Social influence

Social Network Threshold (SNT), (Valente, 1996)

Elements of SNT:

- A threshold is the number of other individuals who must be engaged in an activity before a given individual will join that activity.

- Personal network exposure: leaders, peers and affiliates.

Figure 1: Linking DoI with TAM and inclusion of SNT in the theoretical framework

\section{Research method}

A mixed-method research approach is used. Data is collected and analysed sequentially using two methods: quantitative (survey) and qualitative (interviews). The mixed methods sequential design in this research consists of two distinct phases. First, quantitative data is collected using a questionnaire and analysed. The findings of the quantitative analysis are then used to inform the interviews which are then analysed qualitatively. A pilot trial of the survey instrument is used to test the adequacy and feasibility of a full-scale survey.

The qualitative data and analysis is used to explain the quantitative results by exploring the views of expert practitioners in more depth. For the qualitative stage, interviews were 
undertaken with end users selected from those already having responded to the quantitative survey. Participants in the quantitative survey were invited to volunteer for the interview stage and all volunteers were considered/invited to participate. It is also an advantage to arrange interviews with survey participants who had already addressed potential concerns with the privacy of an organisation or employee workload. The quantitative or statistical data provides a general understanding of a prescribed research problem but provides limited new claims or interpretations. Having the interview participants participate in the interviews helps to ensure consistency of the model testing and to achieve a holistic understanding of the model.

\section{Partial Least Square technique (PLS)}

The main objective of the survey is to obtain data concerning the level of resistance to IT in construction organisations, and to test the significance of the constructs and relationships indicated in the proposed IRFM. A Partial Least Square (PLS) technique is used to evaluate the overall quality of the resistance model, an established technique used in Structural Equation Modelling (SEM). The primary objective of this research is to predict and generate an integrated model of resistance factors that best describe the resistance behaviour of users who have used information technology in construction. PLS provides strong prediction capability in that context (Chin, 1998a; Diamantopoulos, Riefler and Roth, 2008). PLS is also particularly effective in building new models rather than testing established models. This is especially relevant in the context of construction management where there has been relatively little consideration of resistance modelling. The covariance-based approach common in SEM more generally is not effective when the data distribution, as is likely in the current context, does not follow a multivariate normal distribution. PLS deals well with non-normal distributions, it is based on ordinary least square (OLS) regressions, which implies that no assumptions regarding the distribution or measurement scale of observed indicators are required. PLS is considered a soft modelling approach in which no strong assumptions with respect to the distributions are made and PLS works with small sample sizes (Chin and Newsted, 1999). The sample size available to this research is small, with only 88 survey responses. PLS has the ability to run an analysis with a sample size as low as 30 (Chin, 1998b). However, the study treated this advantage with caution, and made moderate assumptions regarding consistency between data and the model because this could be a drawback of the study in the early stage of theory development.

\section{Thematic analysis}

Thematic analysis allows meaning to be associated with and derived from an analysis of thematic frequency. Thematic frequency assumes that language and text are relatively direct in their meaning, and unlikely to lead to an ambiguous interpretation. However, the real focus of thematic analysis is not the frequency but the 'essence' of a text: that is, on what is being said more than how frequently it is being said. Themes can then be explored more flexibly. Even though there is little apparent theory and empirical work specifically representing resistance or on how resistance can be managed, DoI and TAM can still be used to support the building of the codes and themes required for thematic analysis. Thematic analysis can then be used in two different ways at the same time: inductively and deductively (Attride-Stirling, 2001; Boyatzis, 1997; Tuckett, 2005). From an inductive perspective, thematic analysis is best used in early exploration of concepts, interpreting models and theory building. Attride-Stirling (2001) suggests that thematic analysis is the most appropriate method for any study that seeks to explore new ideas using an interpretative approach. 


\section{Research case}

The study used online project information systems (OPIMS) as a research case to test the proposed resistance model. OPIMS is a reference to recent IT innovations introduced to the construction industry, including: web-based project management systems, project extranets, collaboration technologies, online project management technologies, and electronic document management systems (Alshawi and Ingirige, 2003; Andresen, Christensen and Howard, 2003; Björk, 2003; Ilich, Becerik and Aultman, 2006; Nitithamyong and Skibniewski, 2004; Ruikar, Anumba and Carrillo, 2005). OPIMS are relatively mature and robust IT innovation even in the construction industry context. OPIMS is the technology framework that enables collaboration, communication and exchange of construction project information to be supported online. The project information might include project details, project team contacts and email, CAD drawings, specifications, requests for information (RFI's), contract administration, project time and scheduling, safety information, cost estimation, cash flow data and so on.

However, a review of literature showed that the extent of uptake, the adoption and the development of OPIMS remains slow and limited (Andresen, Christensen and Howard, 2003; Gustavsson, Samuelson and Wikforss, 2012; Nitithamyong and Skibniewski, 2004; Samuelson, 2008; 2012). The causes for this slow adoption remain unclear, but with the emergence of building information modelling (BIM) technologies OPIMS seem to have reached a turning point. The turning point refers to the S-shaped diffusion curve and product lifecycle that defines the stages of progression for an innovation. Product life cycle characterises technology innovation in terms of its progression: take-off, saddle, commercialisation, slowdown and substitution (Bass, 1969; Peres, Muller and Mahajan, 2010). Take-off is the period where a new technology is first introduced to the market. The saddle is equivalent to a minor recession situation, where the adoption rate suffers a temporary downturn as a result of weak microeconomic conditions. Adoption increases again when improved generations of the technology begin to appear and grow the market. Commercialisation accelerates growth and adoption through to the final stage of the diffusion, which is maturity. At the maturity stage, technology is well developed and gains wider popularity and consumer acceptance. It does, nevertheless, eventually slowdown again as the substitution stage supersedes current technologies with more advance functionality and performance. At that stage, a new technology will most likely replace the old "innovation".

The diffusion curve also predicts that as an innovation reaches the maturity stage, and is better known in the market, the adoption rate begins to slow. At that point the technology can be considered a success. However, eventually the maturity stage will result in market saturation. At that stage, if improvement or re-invention of the technology does not occur the technology will tend to stagnate. Stagnation can apply to any technology. In the case of OPIMS it is recognised that the technology is an effective management tool, but the rate of take-up has slowed significantly. To gain maximum return from technological investment, organisation may need to seek new strategies to encourage employees to maintain and maximise the use of the technology.

\section{Response rate and characteristic of the sample}

The survey instrument was posted online and a general invitation extended to industry groups and representative bodies to respond. A total of 112 responses were received. Of these, 24 responses were excluded due to invalid responses or because they had no direct link to the use of OPIMS. Of the remaining 88 valid samples in the survey, 65 respondents were male and 23 were female. The sampling frame covered all possible categories of interest, including: different levels of OPIMS user, different levels of employee, permanent employees and cadets. 60 respondents described themselves as a professional and included those employed as a: architect, building surveyor, CAD operator, construction manager, project manager, project 
coordinator, document controller, risk manager, human resources manager, procurement officer and IT manager. The remainder of the respondents (28) were current university students involved in a cadetship, internship or graduate program. In general, the students were undertaking broad roles of contract administrator, construction engineer, architect, or site supervisor.

Following the questionnaire survey, 14 participants volunteered to be involved in follow-up interviews. Participants in the interview varied significantly in their roles, capacity and type of software used. In particular, there was considerable variety in employment: project architect, document controller, contract administrator, construction manager, surveyor, procurement manager, project manager, company director, and cadet. This is useful for this research, as it enables the critical resistance factors to be verified by industry practitioners from a range of different worker and management perspectives. Participants in the interview stage were also varied in terms of their level of expertise and work experience, which ranged from 1 to 20 years.

\section{Quantitative analysis results}

Missing values and descriptive analyses were conducted to produce a clean data set for model estimation and screening. For the 88 valid responses, approximately $1 \%$ of values were missing. According to Little and Rubin (2002), such a low percentage of missing values can be characterised as randomised missing data.

The clean data set was then analysed using the PLS methodology provided by statistical software SmartPLS 2.0 (M3) Beta, developed by Ringle, Wende and Will (2005). The PLS analysis process began by assessing the components in the measurement model. The measurement model is a model linking a set of observed variables (or measurement items) to a latent variable (or construct). It is important to begin with an evaluation of the reliability and validity of the measurement model, as the measurement model becomes the basis for analysing the structural model which represents the overall IRFM. The statistical techniques used for the reliability and validity analysis of the measurement model are significant weight, multicollinearity, nomological validity, and Spearman's correlation coefficient.

The final process is the assessment of the structural model. A structural model is a model linking hypothesised latent variables. The relationships between the variables are assessed using path analysis techniques. The statistical techniques used for structural model assessment are path coefficients, R-square $\left(\mathrm{R}^{2}\right)$ and effect size $\left(f^{2}\right)$. To ensure the overall consistency of the statistical results, a re-sampling technique (bootstrapping) was included.

\section{Measurement model}

There are two applications of PLS to the measurement model: formative and reflective. A formative approach is used to give external shape to each construct in the proposed model based on how the measured items (observed variables) vary relative to each characteristic. The direction of the paths/arrows point from the observed variables (or measurement items) to the constructs. A reflective approach is used to consider the direct causes and effects that underlie each construct (Chin, 1998b). In this case the direction of the arrows is reversed. Because a reflective approach measures underlying structure, the correlations between particular characteristics are far more significant than is the case with a formative approach. Correlations provide the internal consistency of a reflective analysis, and means characteristics can be removed without necessarily impacting on the overall model performance (Jarvis, Mackenzie and Podsakoff, 2003). On the other hand, a formative analysis cannot/need not presume an internal coherence. Where a characteristic has been included on conceptual grounds it is important to retain that characteristic even if there is no apparent correlation. Based on the 
theoretical framework that underlies the proposed model all characteristics and constructs in the measurement model, and therefore also in the structural model, are best represented using a formative approach.

For a formative approach the validity of measures should be determined based on significant weight (Chin, 1998b). The weights, coupled with an associated t-value and p-value, provide evidence for the extent to which particular indicators are statistically significant and explain the variance in the formative items of the model. Conventional cut-off values for significant weights in t-values are 1.65, 1.96 and 2.58 at significant levels (p-values) of 0.1, 0.05 and 0.01, respectively (Chin, 1998b). In a social science context, the ideal p-value is generally taken to be 0.05 (at t-value 1.96) and 0.01 (at t-value 2.58). However, given the exploratory nature of the study, more conservative and substantially higher values have been applied. A p-value of 0.1 ( $t-$ value 1.65) is achievable for this study.

The significant weight results for all measurement items are shown in Table 1. The results reveal that 16 of the estimated formative indicators are statistically insignificant, based on a pvalue of 0.1 (t-value should be greater than 1.65). However, based on consistency with separate Spearman's correlation coefficient analysis (not part of the standard PLS analysis), only six items were removed from the model. The items removed were item Knowledge3 of construct Knowledge, item Use3 of construct Use, items Motivation1 and Motivation3 of construct Motivation, item Advantage3 of construct Advantage and item Visibility2 of construct Visibility. Several items were retained even when the p-value did not reach 0.1 ( $t$-value less than 1.65), namely: items Immediate2, Leader1, Knowledge2, Efficacy2, Anxiety1, Power2, Advantage2, Compatibility2, Complexity2 and Learning2. These items were retained because they are conceptually relevant. Removing these items would have reduced the meaning of the construct. According to the formative principle, items do not need to be correlated or to share similar contents/meaning. Correlation between items should be low because high correlation will imply overlapping items or items that measure the same thing. While the relevance and application of this Spearman's correlation coefficient procedure has not been proven beyond doubt in the PLS domain, it has been successfully applied previously by Haenlein (2004).

Multicollinearity is an analysis used to eliminate redundant items/indicators in the formative model (Diamantopoulos, Riefler and Roth, 2008). However the consequence of eliminating particular items can still remain ambiguous. Diamantopoulos and Winklhofer (2001) claimed that the indicator elimination should not be purely statistical nor separated from the conceptual when a formative measurement model is involved. That would have the potential to mask the true meaning of the construct. For this study, multicollinearity is relevant but it can also complicate the analysis process and create irrelevant values to the research results. To make multicollinearity more straightforward, this measure was treated as a secondary item. Chin (1998b) suggested that the problem of multicollinearity can be ignored if the research focus is at the structural level. Thus, where multicollinearity exists in the statistics, the model is left as it is.

This particular multicollinearity analysis was performed using a multiple regression procedure in SPSS. The variance inflation factor (VIF) and condition index were both used as indicators of multicollinearity. VIF values in the range of 3.5 to 10 , or a condition index itself greater than 10 suggest critical collinearity (Diamantopoulos and Siguaw, 2006). A VIF value below 3.5 is considered an excellent result. In this study, almost all VIF values for the formative variables were less than 3.5. Only one variable (i.e. Compatibility) exceeded 3.879 for VIF, which is still within the index and much less than 10 limit value. The VIF test indicated no multicollinearity problems and confirmed the reliability of the indicators. 
Table 1: Formative constructs, indicators, items and significant weights.

\begin{tabular}{|c|c|c|c|}
\hline Constructs and items & PLS weights & t-statistics & p-value \\
\hline \multicolumn{4}{|l|}{ Resistance } \\
\hline Indicator1 (Time Adoption) -> Resistance & 0.84 & 4.16 & 0.00 \\
\hline Indicator2 (Usage Level) -> Resistance & 0.55 & 2.01 & 0.05 \\
\hline \multicolumn{4}{|l|}{ Leaders } \\
\hline Leaders1 -> Leaders & 0.35 & 1.18 & 0.24 \\
\hline Leaders2 -> Leaders & 0.88 & 3.14 & 0.00 \\
\hline \multicolumn{4}{|l|}{ Peers } \\
\hline Peers1 -> Peers & 0.74 & 2.53 & 0.01 \\
\hline Peers 2 -> Peers & 0.70 & 2.61 & 0.01 \\
\hline \multicolumn{4}{|l|}{ Affiliates } \\
\hline Affiliates1 -> Affiliates & 0.92 & 4.82 & 0.00 \\
\hline Affiliates2 -> Affiliates & 0.33 & 1.28 & 0.20 \\
\hline \multicolumn{4}{|l|}{ Knowledge of ICTs } \\
\hline Knowledge1 -> Knowledge of ICTs & 1.15 & 3.36 & 0.00 \\
\hline Knowledge2 -> Knowledge of ICTs & 0.21 & 0.66 & 0.51 \\
\hline Knowledge3 -> Knowledge of ICTs & -0.45 & 1.36 & $0.18^{* *}$ \\
\hline \multicolumn{4}{|l|}{ Use of ICTs } \\
\hline Use1 -> Use of ICTs & 0.95 & 2.96 & 0.00 \\
\hline Use2 -> Use of ICTs & -0.53 & 1.65 & 0.10 \\
\hline Use3 -> Use of ICTs & -0.35 & 1.00 & $0.32 * *$ \\
\hline \multicolumn{4}{|l|}{ Motivation } \\
\hline Motivation1 -> Motivation & -0.27 & 0.75 & $0.45 * *$ \\
\hline Motivation2 -> Motivation & 0.46 & 1.67 & 0.10 \\
\hline Motivation3 -> Motivation & 0.00 & 0.00 & $1.00^{* *}$ \\
\hline Motivation4 -> Motivation & 0.80 & 2.86 & 0.00 \\
\hline \multicolumn{4}{|l|}{ Efficacy } \\
\hline Efficacy1 -> Efficacy & 1.17 & 4.51 & 0.00 \\
\hline Efficacy2 -> Efficacy & -0.27 & 0.86 & 0.39 \\
\hline \multicolumn{4}{|l|}{ Anxiety } \\
\hline Anxiety1 -> Anxiety & 0.32 & 0.75 & 0.45 \\
\hline Anxiety2 -> Anxiety & 0.76 & 1.84 & 0.07 \\
\hline \multicolumn{4}{|l|}{ Power } \\
\hline Power1 -> Power & 0.91 & 4.54 & 0.00 \\
\hline Power2 -> Power & 0.18 & 0.75 & 0.45 \\
\hline \multicolumn{4}{|l|}{ Advantage } \\
\hline Advantage1 -> Advantage & 0.95 & 2.19 & 0.03 \\
\hline Advantage2 -> Advantage & 0.31 & 0.95 & 0.34 \\
\hline Advantage 3 -> Advantage & -0.26 & 0.72 & $0.47^{* *}$ \\
\hline \multicolumn{4}{|l|}{ Compatibility } \\
\hline Compatibility1 -> Compatibility & 0.84 & 2.42 & 0.02 \\
\hline Compatibility2 -> Compatibility & 0.22 & 0.58 & 0.56 \\
\hline \multicolumn{4}{|l|}{ Complexity } \\
\hline Complexity1 -> Complexity & 0.90 & 3.72 & 0.00 \\
\hline Complexity2 -> Complexity & 0.18 & 0.69 & 0.49 \\
\hline \multicolumn{4}{|l|}{ Learning } \\
\hline Learning1 -> Learning & 1.30 & 3.90 & 0.00 \\
\hline Learning2 -> Learning & -0.48 & 1.09 & 0.28 \\
\hline \multicolumn{4}{|l|}{ Trialling } \\
\hline Trialling1 -> Trialling & -2.08 & 2.37 & 0.02 \\
\hline Trialling2 -> Trialling & 2.68 & 3.15 & 0.00 \\
\hline \multicolumn{4}{|l|}{ Visibility } \\
\hline Visibility 1 -> Visibility & 0.68 & 2.29 & 0.02 \\
\hline Visibility2 -> Visibility & -0.53 & 1.24 & $0.22^{* *}$ \\
\hline Visibility3 -> Visibility & 0.89 & 2.26 & 0.02 \\
\hline
\end{tabular}

\footnotetext{
** Items for deletion
} 


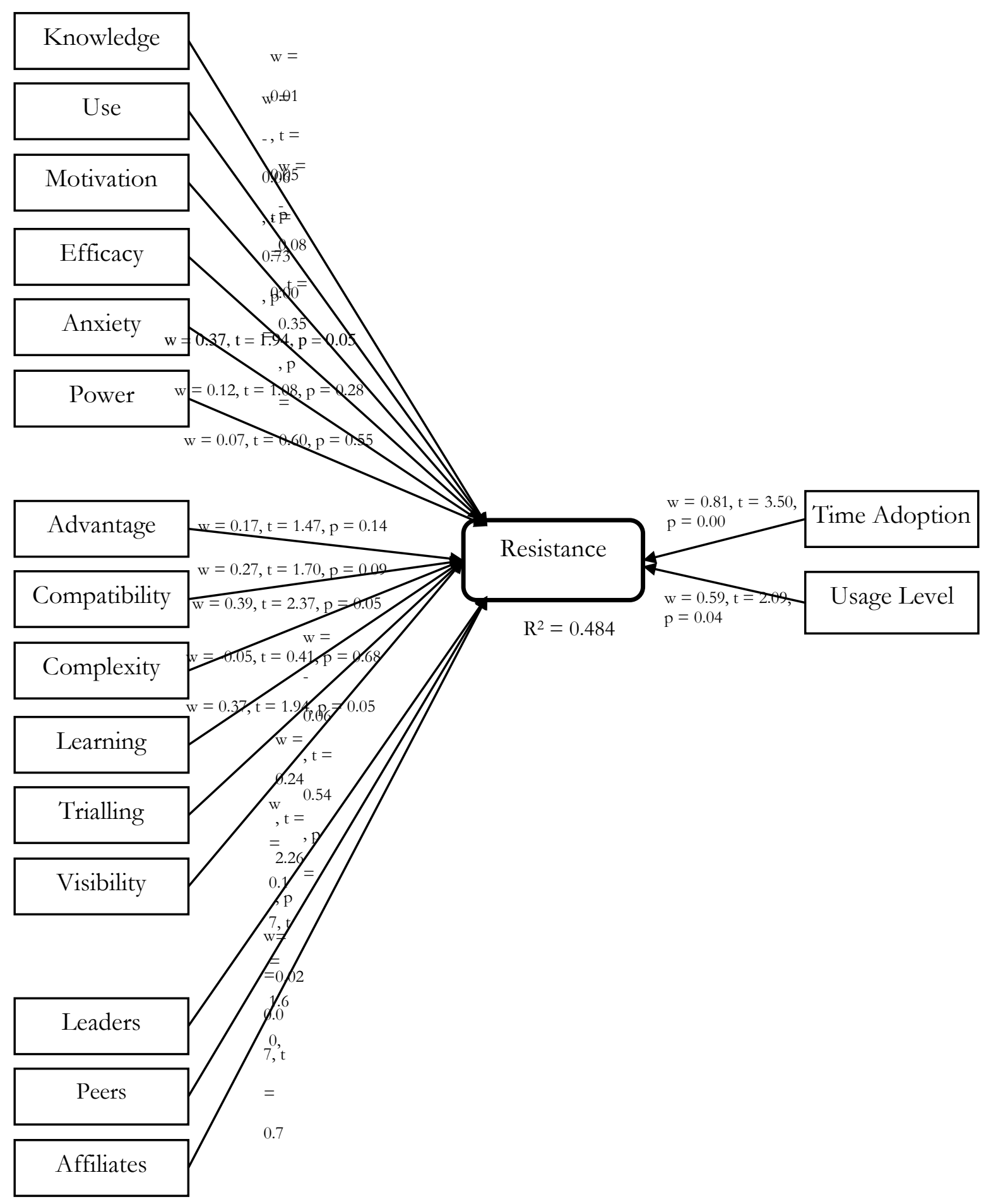

Figure 2: Structural model result

Nomological validity was examined through the standardised path coefficient (or PLS weights) and the significance level of the estimated structural path between the independent constructs and dependent construct (Diamantopoulos, Riefler and Roth, 2008). For the purpose of nomological validity, Resistance was specified as the dependent construct and all other constructs considered as the independent variables. The analysis indicated that several of those independent constructs were not statistically significant drivers of Resistance. For example, the path coefficient (PLS weight) between Affiliates and Resistance was found to be 0.07 , with a pvalue of 0.45 . This is far greater than the acceptable value for the 0.10 level of significance. Other constructs with similarly high PLS weights included: Knowledge of ICTs, Use of ICTs, 
Motivation, Efficacy, Anxiety, Power, Advantage, Learning and Visibility. Given the nature of a formative approach however, none of these constructs have been discarded on statistical grounds alone.

\section{Structural model}

The structural model resulting from the PLS analysis is shown in Figure 2. The structure of the model was assessed using the $\mathrm{R}^{2}$ statistic to find the predictive capability of the model. An $\mathrm{R}^{2}$ measure indicates the extent to which an independent construct helps to predict or explain the dependent construct. It was also evaluated using the t-statistics and p-values of the structural path coefficients (PLS weights) through a re-sampling procedure (bootstrap). Path coefficient values should be in the range of 0.20 to 0.30 , or greater (Chin, 1998a). In Figure 2, the proposed model has a performance $\mathrm{R}^{2}$ value of 0.484 , which is sufficient to conclude that the values are substantive (Chin, 1998b). This result also means that user resistance can be predicted using a combination of all the factors proposed in the IRFM. Overall, the PLS results suggest that the model estimates for the structural model are satisfactory and that the structural model is valid. The overall IRFM explains a reasonably large and acceptable proportion of the variance in user resistance.

In contrast to those constructs that failed the statistical significance tests (Peer, Affiliate, Knowledge, Use, Motivation, Efficacy, Anxiety, Power, Advantage, Learning and Visibility), and are therefore only significant in concert, four constructs emerged as being independently significant (Leaders, Compatibility, Complexity and Trialling). Each of these four constructs may be considered a critical factor in driving user resistance.

There are two limitations of particular note in the PLS technique used in this study. Previous studies have been limited almost exclusively to just multicollinearity and nomological measures (Andreev et al., 2009; Diamantopoulos, Riefler and Roth, 2008; Roberts and Thatcher, 2009). Formal validity analysis techniques for formative design have not been applied or tested extensively. The use of a complementary and simplified correlation procedure based on Spearman's correlation coefficient has only been applied successfully once previously, in a study on e-business success factors by Haenlein (2004). With novelty, there is always the potential for results to be compromised. Notwithstanding the lack of track record however, the utility of the approach in this particular research context strongly recommends that future studies dealing with formative design use Spearman's correlation coefficient to assess validity.

The second limitation of PLS as used in this study is in respect to the sample size. A small sample size will always limit both the quantitative and qualitative aspects of any study. A sample size of 88 is generally deemed to be sufficient for the purposes of model testing using PLS (Chin, 1998b; Chin and Newsted, 1999). However, the possibility of bias in the data remains, and future research would usefully involve a larger sample for both the quantitative and qualitative studies and a broader population of construction practitioners.

\section{Qualitative analysis results}

For the purposes of a qualitative analysis, the IRFM factors were grouped under 4 broad themes: support network, experience and disposition, integration and technical problems, and accessible learning and training. Using keywords derived from each resistance factor, a thematic analysis of interview transcripts was undertaken. The interviews were conducted subsequent to the quantitative analysis, with the dual intention of: to deepen understanding and explain or elaborate on the quantitative results obtained; and to better understand how construction organisations respond to and seek to manage user resistance specific to OPIMS.

Fourteen participants were involved in the interviews. Interview participants were identified from the 29 survey participants already in the survey database, who had indicated their 
willingness to participate. They are vary widely in their roles, and from a range of different management functions e.g. construction manager, engineer, project architect, document controller, and software provider. The interview participants also have varying levels of work experience in the construction industry, ranging from one to 20 years. This ensures that the research has a variety of end-user perspectives across different levels of experience and expertise.

\section{General observations}

A key distinction was commonly made between 2 user groups: assigned users and guest users. In the interview, Participant $M$, from an OPIMS software provider, stated: "you can have many people sign-up or log in to [OPIMS], but there may only be a few people who understand and use the software regularly. Some of the people are active users and some are guest users. A person is considered an active user when they have the role of project admin, document controller, contract admin and so on - we can call them the 'power user'. These are people who could influence others to use [OPIMS]". Participant $\boldsymbol{B}$, a document controller who uses two different types of OPIMS to manage documents for multiple projects, stated: "not all [OPIMS] users are active users - some of them are guest users. From 482 users registered in [OPIMS], only 70 of them are registered across my company nationwide. They are people who deal with the software and probably use the software quite often". It is apparent that certain users (assigned users) use OPIMS as an integral part of their work function and can demonstrably improve the effectiveness of their work as a consequence. This group is best placed to empower others to use the software. Another group (guest users) are less implicated in the use and operation of OPIMS and obtain less advantage from the its use. Guest users may use OPIMS for managing the overall communication process of a project, its documentation, or to address transparency issues, but in that context the benefits are less significant. It can be inferred that the commitment to use OPIMS for a guest user has more to do with communication exchange and social connection than it has to do with their specific job function.

Another strong observation from the interviews is that user attitudes remain generally positive about OPIMS. Most interview participants stated that they were personally comfortable with OPIMS. Interestingly, a number also expressed the view that it is to be expected that some users will be reluctant (or resistant) to engage with OPIMS. For example, Participant $D$, a construction manager who is also the managing director of a small-to-medium construction enterprise, stated: "Our employees use this software and sub-contractors too. Employees have an obligation to use the software, definitely. But for sub-contractors, we cannot press that on them. Many sub-contractors are old and traditional, and may not be internet savvy. For example, we have a very skilful tiling contractor who offers a cheap price. He doesn't really want to use this software. We cannot risk our relationship with that sub-contractor just because they refuse to use this software. They offer us a reasonable price and very skilful labour. We have our procurement manager to help them upload and download drawings". From this and similar views, it can be seen that the adoption of OPIMS is context dependent and influenced by user attitudes. For example, there may be little need for an OPIMS application for a small construction business where, say, the requirement may be limited to the infrequent transfer of relatively small drawing files.

\section{Verifying critical factors that influence resistance}

Easily the most consistent theme expressed by participants with respect to resistance and support for using OPIMS was the importance of leaders and managers. The role of the manager, whether internal or external to a company, is generally regarded as being critical. The nature of the work on construction projects is broadly framed by the organisational structure of 
project joint ventures. The multi-organisational composition of a construction project leads to increased interdependency and interactivity among members of the team. That dependency extends to how OPIMS is utilised and the strong need for effective support from peers and coworkers in order to function effectively in any particular role. The reliance on others accounts for the significant influence that leader, peer and co-worker relationships have on motivation in general, and on adoption of OPIMS more specifically. Of course dependency and support are two way streets. The offer of support to provide relevant assistance to sub-contractors (see Participant $D$ above), whilst demonstrating leadership and support, can enable workers (subcontractors) to avoid use of OPIMS. Participants point to leaders and managers as the key people to provide advice and guidance when dealing with innovations such as OPIMS.

In contrast to the significance of leaders and managers, a number of the experience and disposition factors were generally perceived by interview participants as having little influence on user resistance, namely: Knowledge of ICTs, Use of ICTs, Motivation, Efficacy, Anxiety and Power. Participants frequently expressed a positive attitude towards these factors, as aspects they could change and adapt to accommodate new OPIMS technologies. There was definite confidence on the part of interview participants that these particular experience and disposition factors could be addressed or overcome, and did not therefore represent a significant barrier to OPIMS adoption and use.

The expressed opinions of interview participants about the integration of OPIMS at work were more varied. The variation seemed to depend on the profession role and particular work tasks of a user. For example, document controllers and contractors were largely in agreement that OPIMS is simple, easy and intuitive. In contrast, architects and engineers tended to focus on the difficulties and problems of matching flexible work practices with relatively prescribed OPIMS activities. For example, Participant $K$ (an engineer) said: "I understand why somebody would be less favourable towards this system. There is some frustration with technical aspects. Certain of them [the users] are unfamiliar with it, and they are sceptical that this software can greatly improve their working methods. The software will certainly increase efficiency in some situations, but in other circumstances it may actually slow down the process. For example, while working onsite and briefing sub-contractors, I cannot rely on my tablet [computer] only, because it has limited views and usually the greater complexity of a project, the bigger the scale of engineering details drawn for them. So an A1 drawing, not an iPad, is required". Participant $A$, (an architect) stated: "This is really a superb piece of software, easy to use and well presented, keeping track of project documents. But for us [architects] this software is not really the main application. In our office, we mostly use AutoCAD for drafting, although we do own Revit as well. Other software commonly used is SketchUp and Photoshop. There are other platforms out there that allow some really amazing 3D work but our clients generally don't request that level of visualisation".

Most participants in this study agreed that training is an important factor in influencing resistance. Training can be seen to be much more than just building skills and knowledge. Training also has a raft of other personal and career benefits. The study found that training methods are being seriously disrupted by internet and related technologies. Traditional face-toface training increasingly is being supplemented or replaced by interactive video tutorials containing information and instructions on how to operate the technology. Conventional training methods no longer adequately prepare OPIMS users for continuous learning, which increasingly demands online and on-demand teaching support. At this point in time, a combination of face-to-face and online training and support appears to offer the best overall learning experience. Training must be relevant and useful if it is to be more engaging and better motivate learners. 


\section{Key strategies to overcome resistance}

Rather than articulate specific strategies to overcome user resistance, the majority of interview participants referred to particular factors and discussed various potential training and support initiatives. The implication of this is that training and support are the two key strategies to overcome user resistance. Traditionally, support is viewed relative to individual motivation, where training is linked more with the capacity to learn. A number of participants did suggest that a combination of motivation and learning would be ideal. In that regard, face-to-face training is seen to have distinct advantages over online training when it comes to integrating training with social support. However, the changing social practices associated with emerging online communication may reverse those advantages in the future.

\section{Conclusions}

The main aim of this research is to develop a comprehensive model of the key resistance factors that shifts the focus of innovation from promoting adoption to dealing with resistance. Moving research attention in this way exposes a new set of variables and, consequently, new possibilities to improve the rate and extent of technological innovation. Resistance is not only a marker for possible user intransigence, it can also be a highlight for dysfunctional or ineffective technology. As such, the IRFM proposed in this study offers a new perspective on technology innovation where previously user dissatisfaction and dysfunctional technology was being masked. This masking most occurs when a technology reaches the level of maturity that OPIMS has now reached in the construction industry.

The developed IRFM has been tested and validated using a quantitative analysis of survey results. The IRFM explains a reasonably large and acceptable proportion of the variance in user resistance. Four particular constructs emerged as being independently significant (Leaders, Compatibility, Complexity and Trialling). Each of these four constructs may be considered a critical factor in driving user resistance.

A series of follow-up interviews conducted to validate the findings identified training and support as the two key strategies to overcome user resistance. Notwithstanding the changing use of social media, face-to-face training is still regarded as the preferred combination of training and support strategies.

This study is specific to the use of OPIMS in Australia. However, the proposed IRFM has more generic relevance, in terms of both jurisdiction and the stage of technological innovation. Further research is required to test that potential and is especially encouraged in the context of building information modelling (BIM). There are many substantial initiatives internationally to promote greater uptake of BIM, where adoption appears to have stalled somewhat (Cousins and Knutt, 2016). This study suggests that a focus on resistance rather than adoption could be more beneficial, even for a relatively immature innovation such as BIM.

\section{References}

Alshawi, M. and Ingirige, B., 2003. Web-enabled project management: An emerging paradigm in construction. Automation in Construction, 12(4), pp.349-64. doi: http://dx.doi.org/10.1016/S0926-5805(03)00003-7

Andreev, P., Heart, T., Maoz, H. and Pliskin, N., 2009, Phoenix, Arizona.

Andresen, J.L., Christensen, K. and Howard, R.W., 2003. Project management with a project web. Journal of Information Technology in Construction, 8, pp.29-41.

Attride-Stirling, J., 2001. Thematic networks: An analytic tool for qualitative research. Qualitative Research, 1(3), pp.385-405. doi: http://dx.doi.org/10.1177/146879410100100307

Bass, F.M., 1969. A new product growth model for consumer durables. Management science, 15(5), pp.215-27. doi: http://dx.doi.org/10.1287/mnsc.15.5.215

Benbasat, I. and Barki, H., 2007. Quo vadis TAM. Journal of the Association for Information Systems, 8(4), pp.211-8.

Björk, B.-C., 2003. Electronic document management in construction - research issues and results. Journal of Information Technology in Construction, 8, pp.105-17. 
Boyatzis, P., 1997. Transforming qualitative information: Thematic analysis and code development. Oxford: Sage Publications.

Cenfetelli, R.T., 2004. Inhibitors and enablers as dual factor concepts in technology usage. Journal of the Association for Information Systems, 5(11/12), pp.475-92.

Chin, W.W., 1998a. Commentary: Issues and Opinion on Structural Equation Modeling. MIS Quarterly, 22(1), pp.vii-xvi.

Chin, W.W., 1998b. Partial least squares approach for structural equation modeling. In: G.A. Marcoulides ed. Modern methods for business research. Mahwah, N.J.: Lawrence Erlbaum. pp.295-336.

Chin, W.W. and Newsted, P.R., 1999. Structural equation modeling analysis with small samples using partial least squares. In: R. Hoyle ed. Statistical strategies for small sample research. Thousand Oaks, CA: Sage Publications. pp.1307-41.

Cousins, S. and Knutt, E., 2016. BIM: What users really think [e-book]. London: Atom Publishing http://www.constructionmanagermagazine.com/bim-whitepaper [Accessed 10 April 2016].

Davis, F.D., 1986. A technology acceptance model for empirically testing new end-user information systems : theory and results. $\mathrm{PhD}$, Sloan School of Management., Massachusetts Institute of Technology.

Davis, F.D., Bagozzi, R.P. and Warshaw, P.R., 1989. User acceptance of computer technology: A comparison of two theoretical model. Management science, 35(8), pp.982-1003. doi: http://dx.doi.org/10.1287/mnsc.35.8.982

Davis, K.A., 2004. Information technology change in the architecture, engineering, and construction industry: An investigation of individuals' resistance. PhD, Virgina Polytechnic Institue and State University, Blacksburg, VA.

Diamantopoulos, A., Riefler, P.A. and Roth, K.P., 2008. Advancing formative measurement models. Journal of Business Research, 61, pp.1203-18. doi: http://dx.doi.org/10.1016/j.jbusres.2008.01.009

Diamantopoulos, A. and Siguaw, J.A., 2006. Formative versus reflective indicators in organizational measure development: A comparison and empirical illustration. British Journal of Management, 17, pp.263-82. doi: http://dx.doi.org/10.1111/j.1467-8551.2006.00500.x

Diamantopoulos, A. and Winklhofer, H., 2001. Index construction with formative indicators:an alternative to scale development. Journal of Marketing Research, 38(2), pp.269-77. doi: http://dx.doi.org/10.1509/jmkr.38.2.269.18845

Ferneley, E.H. and Sobreperez, P., 2006. Resist, comply or workaround? An examination of different facets of user engagement with information systems. European Journal of Information Systems, 15(4), pp.345-56. doi: http://dx.doi.org/10.1057/palgrave.ejis.3000629

Granovetter, M.S., 1973. The strength of weak ties. American journal of sociology, 78(6), pp.1360-80. doi: http://dx.doi.org/10.1086/225469

Gustavsson, T.K., Samuelson, O. and Wikforss, O., 2012. Organizing IT in construction: Present state and future challenges in Sweden. Journal of Information Technology in Construction, 17, pp.520-34.

Haenlein, M., 2004. An Exploratory Investigation of E-business Success Factors Using Partial Least Squares Analysis. PhD, Otto Beishem Graduate School of Management.

Hartmann, T. and Fischer, M., 2009. A process view on end user resistance during construction IT implementations. Journal of Information Technology in Construction, 14, pp.353-65.

Ilich, M., Becerik, B. and Aultman, B., 2006. Online collaboration: Why aren't we using our tools? Construction Zone, 6(3), pp.10-4.

Jarvis, C.B., Mackenzie, S.B. and Podsakoff, P.M., 2003. A critical review of construct indicators and measurement model misspecification in marketing and consumer research. Journal of Consumer Research, 30(September), pp.199-218. doi: http://dx.doi.org/10.1086/376806

Jeyaraj, A., Rottman, J.W. and Lacity, M.C., 2006. A review of the predictors, linkages, and biases in IT innovation adoption research. Journal of Information Technology, 21(1), pp.1-23. doi: http://dx.doi.org/10.1057/palgrave.jit.2000056

Joshi, K., 1991. A model of users' perspective on change: the case of information systems technology implementation. MIS Quarterly, 15(2), pp.229-42. doi: http://dx.doi.org/10.2307/249384

Kim, H.-W. and Kankanhalli, A., 2009. Investigating user resistance to information systems implementation: A status quo bias perspective. MIS Quarterly, 33(3), pp.567-82.

Klaus, T., Wingreen, S.C. and Ellis, B.J., 2010. Resistant groups in enterprise system implementations: a Qmethodology examination. Journal of Information Technology, 25(91-106). doi: http://dx.doi.org/10.1057/jit.2009.7

Lapointe, L. and Rivard, S., 2005. A multilevel model of resistance to information technology implementation. MIS Quarterly, 29(3), pp.461-91.

Laumer, S. and Eckhardt, A., 2010, St. Louis (MO).

Legris, P., Ingham, J. and Collerette, P., 2003. Why do people use information technology? A critical review of the technology acceptance model. Information \& Management, 40(3), pp.191-204. doi: http://dx.doi.org/10.1016/S0378-7206(01)00143-4

Little, R.J.A. and Rubin, D.B., 2002. Statistical analysis with missing data: Wiley. doi: http://dx.doi.org/10.1002/9781119013563

Marakas, G.M. and Hornik, S., 1996. Passive resistance misuse: Overt support and covert recalcitrance in is implementation. European Journal of Information Systems, 5(3), pp.208-19. doi: http://dx.doi.org/10.1057/ejis.1996.26 
Martinko, M.J., Henry, J.W. and Zmud, R.W., 1996. An attributional explanation of individual resistance to the introduction of information technologies in the workplace. Behaviour \& Information Technology, 15(5), pp.313-30. doi: http://dx.doi.org/10.1080/014492996120085a and http://dx.doi.org/10.1080/014492996120094

Meissonier, R. and Houzé, E., 2010. Toward an 'IT Conflict-Resistance Theory': action research during IT preimplementation. European Journal of Information Systems, 19(5), pp.540-61. doi: http://dx.doi.org/10.1057/ejis.2010.35

Moore, G.C. and Benbasat, I., 1991. Development of an instrument to measure the perceptions of adopting an information technology innovation. Information Systems Research, 2(3), pp.192-222. doi: http://dx.doi.org/10.1287/isre.2.3.192

Nitithamyong, P. and Skibniewski, M.J., 2004. Web-based construction project management systems: How to make them successful? Automation in Construction, 13(4), pp.491-506. doi: http://dx.doi.org/10.1016/j.autcon.2004.02.003

Orlikowski, W.J., 2000. Using Technology and Constituing Structures: A Practice Lens for Studying Technology in Organizations. Organization Science, 11(4), pp.404-28. doi: http://dx.doi.org/10.1287/orsc.11.4.404.14600

Peres, R., Muller, E. and Mahajan, V., 2010. Innovation diffusion and new product growth models: A critical review and research directions. International Journal of Research in Marketing, 27, pp.91-106. doi: http://dx.doi.org/10.1016/i.ijresmar.2009.12.012

Prasad, P. and Prasad, A., 2000. Stretching the iron cage: The constitution and implications of routine workplace resistance. Organization Science, 11, pp.387-403. doi: http://dx.doi.org/10.1287/orsc.11.4.387.14597

Ringle, C.M., Wende, S. and Will, A., 2005. SmartPLS 2.0: www.smartpls.de.

Roberts, N. and Thatcher, J., 2009. Conceptualizing and testing formative constructs: tutorial and annotated example. SIGMIS Database, 40(3), pp.9-39. doi: http://dx.doi.org/10.1145/1592401.1592405

Rogers, E.M., 1962. Diffusion of Innovations. 4th ed. New York, NY: Simon and Schuster.

Rogers, E.M., 2003. Diffusion of innovations. 5th ed. New York: Free Press.

Rogers, E.M. and Kincaid, L., 1981. Communication Networks: Towards a new Paradigm for research. 4th ed. New York, NY: Free Press.

Ruikar, K., Anumba, C.J. and Carrillo, P.M., 2005. End-user perspectives on use of project extranets in construction organisations. Engineering, Construction and Architechtural Management, 12(3), pp.222-35. doi: http://dx.doi.org/10.1108/09699980510600099

Salovaara, A. and Tamminen, S., 2009. Acceptance or appropriation? A design-oriented critique of technology acceptance models. In: H. Isomäki and P. Saariluoma eds. Future Interaction Design II: Springer London. pp.15773. doi: http://dx.doi.org/10.1007/978-1-84800-385-9 8

Samuelson, O., 2008. The IT-barometer - a decade's development of IT use in the Swedish construction secotr. ITcon, 13, pp.1-19.

Samuelson, O., 2012. IT-Barometern 2011: En mätning av bygg- och fastighetssektorns IT-användning. KTH Royal Institute of Technology. Stockholm.

Tuckett, A.G., 2005. Applying thematic analysis theory to practice: A researcher's experience. Contemporary Nurse, 19(1-2), pp.75-87. doi: http://dx.doi.org/10.5172/conu.19.1-2.75

Val, M.P.d. and Fuentes, C.M., 2003. Resistance to change: A literature review and empirical study. Management Decision, 41(2), pp.148-55. doi: http://dx.doi.org/10.1108/00251740310457597

Valente, T., 1996. Social Network Thresholds in the Diffusion of Innovations. Social networks, 18, pp.69-89. doi: http://dx.doi.org/10.1016/0378-8733(95)00256-1

Valente, T. and Davis, R.L., 1999. Accelerating the Diffusion of Innovations using opinion leaders. The Annals of the American Academy of Political and Social Science, 566(1), pp.55-67. doi: http://dx.doi.org/10.1177/0002716299566001005

Venkatesh, V., 2006. Where to go from here? Thoughts on future directions for research on individual-level technology adoption with a focus on decision making. Decision Sciences, 46(2), p.186. doi: http://dx.doi.org/10.1111/j.1540-5414.2006.00136.x

Venkatesh, V. and Davis, F.D., 2000. A theoretical extension of the Technology Acceptance Model: Four longitudinal field studies. Management science, 46(2), p.186. doi: http://dx.doi.org/10.1287/mnsc.46.2.186.11926

Venkatesh, V., Morris, M.G., Davis, G.B. and Davis, F.D., 2003. User acceptance of information technology: Towards a unified view. MIS Quarterly, 27(3), pp.425-78.

Waddell, D. and Sohal, A.S., 1998. Resistance: A constructive tool for change management. Management Decision, Vol. 36 Iss: 8, pp.543 - 548, 36(8), pp.543-8.

Williams, M.D., Dwivedi, Y.K., Lal, B. and Schwarz, A., 2009. Contemporary trends and issues in IT adoption and diffusion research. Journal of Information Technology, 24(1), pp.1-10. doi: http://dx.doi.org/10.1057/jit.2008.30 